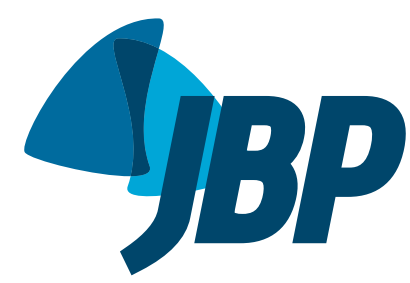

1. Programa de Pós-Graduação em Clínica Médica, Universidade Federal do Rio de Janeiro, Rio de Janeiro (RJ) Brasil.

2. Instituto de Estudos em Saúde Coletiva, Universidade Federal do Rio de Janeiro, Rio de Janeiro (RJ) Brasil.

3. Faculdade de Medicina, Universidade Federal do Rio de Janeiro, Rio de Janeiro (RJ) Brasil.

4. Instituto Fernandes Figueira/Fundação Oswaldo Cruz - IFF/Fiocruz Rio de Janeiro (RJ) Brasil.

a. (ID) http://orcid.org/0000-0001-7348-5502

b. (iD http://orcid.org/0000-0002-7784-9905

c. (iD http://orcid.org/0000-0003-3116-0253

d. (iD http://orcid.org/0000-0003-1727-502X

Submitted: 19 August 2017.

Accepted: 18 April 2018.

Study carried out at the Universidade Federal do Rio de Janeiro, Rio de Janeiro (RJ) Brasil.

\section{Asthma mortality in Brazil, 1980-2012: a regional perspective}

\author{
Thaís de Sá Brito1,a, Ronir Raggio Luiz²,b, José Roberto Lapa e Silva ${ }^{3, c}$, \\ Hisbello da Silva Campos ${ }^{4, d}$
}

\begin{abstract}
Objective: To estimate asthma mortality rates in Brazil for the period 1980-2012. Methods: On the basis of data from the Brazilian National Ministry of Health Mortality Database, we estimated mortality rates by calculating moving averages from a municipal perspective that would allow an evaluation differentiating between urban, rural, and intermediate (rurban) Brazil during the period 2002-2012. Trends were assessed using simple linear regression. Results: On average, 2,339 asthma-related deaths were reported per year during the study period. Asthma ranged from the 53rd to 95th leading cause of death. There was a decrease in asthma mortality rates in the country, from $1.92 / 100,000$ population in 1980 to $1.21 / 100,000$ population in 2012. From the municipal perspective, rates fell in urban and rurban Brazil, but increased in rural Brazil, except in the 5-34-year age group. Asthma mortality rates fell in the population under 25 years of age and increased among those over 74 years of age. Rates were always higher in females. Conclusions: Asthma mortality rates in Brazil have been decreasing slightly, with the decrease being more marked in the decade 2002-2012. Only the northeastern region of Brazil showed the opposite trend. Asthma mortality rates in urban and rurban Brazil showed a downward trend similar to that of the national scenario, whereas rural Brazil showed the opposite behavior. Analysis by age group showed that rates decreased among younger individuals and increased among the elderly aged $\geq 75$ years.
\end{abstract}

Keywords: Asthma/mortality; Brazil; urban population; rural population.

\section{INTRODUCTION}

Globally, asthma affects $1-16 \%$ of the population in different countries (approximately 300 million people)(1) and causes 346,000 deaths annually. (2) Two epidemics of asthma mortality were described in the 20th century: the first one, in the 1960s, in the United Kingdom, Australia, and New Zealand; and the second one, a decade later, in New Zealand. The first epidemic was attributed to a cardiotoxic effect of high doses of isoprenaline. The second epidemic was associated with the widespread use of fenoterol and other potentially cardiotoxic inhaled bronchodilators. ${ }^{(3-6)}$

Measuring the impact of asthma mortality not only from a national but also from a regional perspective is particularly important in countries of continental dimensions where there is regional diversity in socioeconomic, development, and infrastructure conditions. Different epidemiological scenarios emerge when intra-urban differentials are included in prevalence studies.

Urbanization, on one hand, can have negative effects on human health that result from aspects of living and housing conditions and air pollution and, on the other, can improve the provision of health services, positively influencing human health. ${ }^{(7)}$ The results obtained will be better if regional differences are taken into account in planning and scheduling control measures, regardless of the regional degree of urbanization. ${ }^{(8-10)}$
Asthma mortality rates and their trends are presented from a national and macro-regional perspective and from a municipal perspective. From this latter perspective, the Instituto Brasileiro de Geografia e Estatística (IBGE, Brazilian Institute of Geography and Statistics) divides the country into two areas: urban and rural. Whereas the first (an urban area) is defined as "an area within the urban perimeter, created by a municipal law, whether for tax or urban planning purposes (Master Plan, zoning, etc.)," the second (a rural area) is defined as "an area that was not included in the urban perimeter by a municipal law."(11) Because this classification can generate bias in the analysis of access to and efficiency of health care when focusing on populations of municipalities considered rural and bordering large urban areas, the municipal analysis performed in the present study was based on the urban and rural area definitions established by José Eli da Veiga, ${ }^{(12)}$ which have been validated by several authors and are described below.

\section{METHODS}

The behavior of asthma mortality rates for the period 1980-2012 was analyzed on the basis of official data from the Mortality Database of the Departamento de Informática do Sistema Único de Saúde (DATASUS, Information Technology Department of the Brazilian Unified Health Care System), which are available for

Endereço para correspondência:

Thaís de Sá Brito and Hisbello da Silva Campos. Rua do Catete, 311, Sala 714, CEP 22220-001, Rio de Janeiro, RJ, Brasil.

Tel.: 5521 2245-5614. E-mail: ts.brito@yahoo.com.br and hisbello@hotmail.com

Financial support: This study received financial support from the Academic Excellence Program of the Brazilian Coordenação de Aperfeiçoamento de Pessoal de

Nive/ Superior/Ministry of Education and Culture (CAPES, Office for the Advancement of Higher Education/MEC; (CAPES/PROEX; protocol 1964/2013). 
the population. Searching for information on the site followed this sequence: 1 ) health information and vital statistics; 2) filter: general mortality, in Brazil by region and state/Federal District, and asthma as the cause of death; 3) deaths by occurrence; 4) year of death; 5) gender, age, and municipality of occurrence. For the period 1980-1995, we used the International Classification of Diseases (ICD) 9th revision (ICD-9; code 493: asthma); for the period 1996-2012, we used the ICD 10th revision (ICD-10; code J45: asthma, and code J46: acute severe asthma). Rates were calculated by gender, age group, macro-region, and municipality group. The period chosen was the one for which there was complete information in the DATASUS database.

Analysis of mortality rates by gender, age group, and macro-region was performed by simple linear regression, for the period 1980-2012. Analysis of mortality rates by municipality group was performed only from 2002-2012 and was carried out by calculating moving averages; subsequently, trend averages were evaluated by simple linear regression. We chose to perform the analysis by municipality group only from 2002 onward because, in 2001, 54 new municipalities were created in Brazil, and this would disrupt the analysis, since many municipalities are created within existing ones. Therefore, the analysis was made on the basis of 5,564 municipalities.

Asthma mortality rates were calculated as follows: absolute number of deaths $\times 100,000 /$ population. In the analysis by gender, we used the male and female populations for each year. In the analysis by age, the age groups were defined according to the classification used by the Pan American Health Organization and the DATASUS. ${ }^{(13)}$ In the analysis of mortality rates by municipality, we used the population in each municipality for each year and we did the same calculation.

Given that studies on asthma mortality usually analyze the 5-34-year age group separately as a marker of global rates, because, in this group, there is less bias of diagnostic confusion with bronchiolitis and especially with $\mathrm{COPD},{ }^{(3,14)}$ all rates calculated were compared with the corresponding ones for this age group.

The classification used by the IBGE defines city as the seat of a municipality. In this classification, every municipality seat (city) and every district seat (village) is considered an urban area. A decree issued in 1938, during the Estado Novo regime, transformed all municipal seats into cities, which resulted in the classification used by the IBGE considering any municipal seat to be urban, ${ }^{(11)}$ regardless of its demographic characteristics. This standard may lead to significant biases in the analysis of access to health care by a population residing in a small municipality bordering a large metropolitan center. Even if that municipality has only a minimum health structure, its population has access to health care in the neighboring large metropolitan center. Therefore, if the classification used by the IBGE is applied, the population of that municipality would be considered rural even if, in practice, they have access to health care in the same way as the urban population of the large metropolitan center. Consequently, several authors and institutions have preferred to use another classification of urban or rural population that has been validated and takes other demographic factors into account. This classification, proposed by Veiga, ${ }^{(12)}$ uses a methodology that is more appropriate to local municipal conditions, combining municipality population size (large, medium, or small) with population density and level of urbanization: municipalities within metropolitan areas (MA) and municipalities outside MA. ${ }^{(12)}$ In this methodology, in addition to the concepts of urban-municipalities within MA, by size (large, medium, or small), and large municipalities outside MA-and rural-small municipalities outside MA-there is a new concept: "rurban"-medium municipalities outside MA. This classification eliminates the potential bias mentioned above and was used for the municipal analysis of asthma mortality rates and their trends in Brazil in the present study.

For calculation purposes, for municipalities within MA, we used the sum of the populations of municipalities within MA in Brazil; likewise, the sum of the populations of municipalities outside MA was calculated. The study included 5,564 municipalities. The classification used to categorize them by size was as follows ${ }^{(12)}$ :

- Large: more than 100,000 inhabitants

- Medium: population between 50,000 and 100,000 inhabitants or population density $\geq 80$ inhabitants $/ \mathrm{km}^{2}$, even if there were fewer than 50,000 inhabitants

- Small: fewer than 50,000 inhabitants and population density $<80$ inhabitants $/ \mathrm{km}^{2}$

Since the analysis also took the level of urbanization into account, all of the 5,564 Brazilian municipalities were further divided into two groups: those within MA and those outside MA.

Statistical analysis was performed with the IBM SPSS Statistics software package, version 24.0 (IBM Corporation, Armonk, NY, USA). Linear regressions were performed with $95 \%$ confidence intervals for slope coefficients. In the municipal analysis, moving averages of linear coefficients were used to smooth the time series. The study was approved by the Research Ethics Committee of the Oswaldo Cruz Foundation Fernandes Figueira Institute.

\section{RESULTS}

Asthma ranged from the 53rd to 95th leading cause of death in Brazil during the study period. On average, there were 2,339 asthma-related deaths per year in the country between $1980(n=2,286)$ and 2012 ( $n=2,354$ ). Figure 1 shows asthma mortality rates per 100,000 population. During the study period as a whole, there is a slight downward overall trend in rates $(-0.007)$, which decreased from $1.92 / 100,000$ population in 1980 to $1.21 / 100,000$ population in 2012 . The trend was not uniform, there being alternation between decrease (1980-1991; 1999-2005; 2006-2012) 
and increase (1992-1999; 2005-2006), similarly to what occurred in the 5-34-year age group $(-0.002$ deaths/year), giving consistency to the data.

Figure 2 shows that asthma mortality rates were significantly higher in females, and this difference increased over the years. The highest mortality rates were found in the 75 years and over age group (20.37/100,000 population, on average). The lowest rates were observed in the 15-24-year age group $(0.20 / 100,000$ population, on average). A proportional analysis of asthma-related deaths by age group (Figure 3) demonstrated that participation in the proportion of deaths increased over time from age 25 years and over, the increase being marked in the 75 years and over age group ( $17.6 \%$ of deaths in 1980 vs. $40.8 \%$ in 2012). Participation in the proportion of deaths decreased among those under 25 years of age, especially in the 0-4-year age group. The 5-14-year age group had the lowest proportion of asthma-related deaths, followed by the 15-24-year age group. From a macro-regional perspective (Figure 4), rates decreased slightly in the North ( -0.004 deaths/year), Southeast ( -0.023 deaths/year), South $(-0.017$ deaths/year), and Central-West ( -0.007 deaths/year). The only exception was the Northeast, where there was a slight increase in mortality rates (0.025 deaths/year). Mean mortality rates (per 100,000 population) in each region for the period 1980-2012 were as follows: 1.73 (in the South); 1.58 (in the Southeast); 1.48 (in the Northeast); 1.10 (in the Central-West); and 0.79 (in the North).

The temporal evolution of moving averages of asthma mortality rates was analyzed by type of municipality, as defined above. Rates decreased in municipalities within MA and in municipalities outside MA (Figure 5).

Urban Brazil comprises large, medium, and small municipalities within MA and large municipalities outside MA. A detailed analysis of urban Brazil showed a downward trend in the moving averages of asthma mortality rates for large municipalities (both within and outside MA). The same was observed in "rurban" Brazil. However, the opposite was observed in medium and small municipalities within MA, where asthma mortality increased. In rural Brazil, represented by small municipalities outside MA, the moving averages of asthma mortality rates showed an upward trend (0.11 per year; Figure 6).

Analysis of the population aged 5-34 years corroborates the above findings, except for rural Brazil,

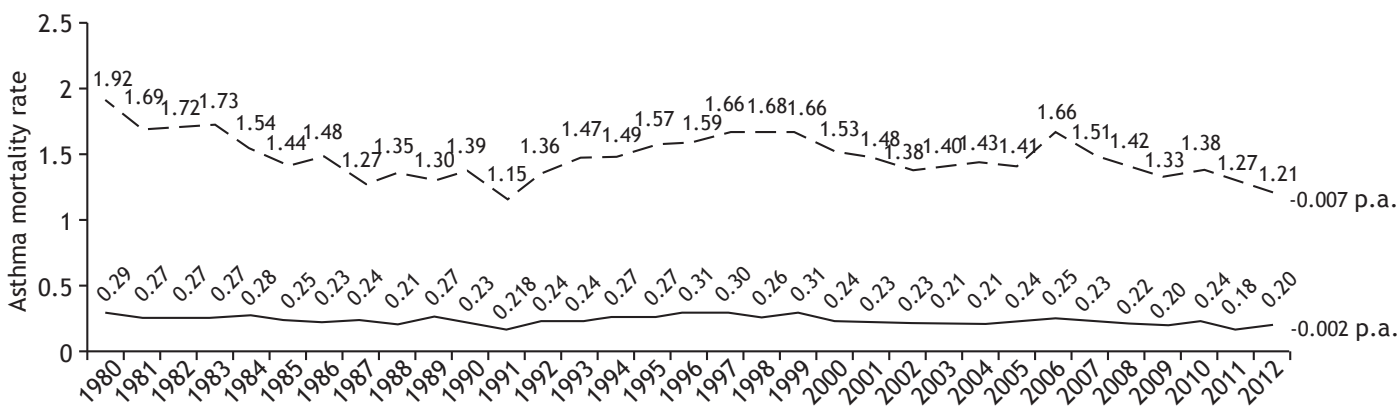

Year

\begin{tabular}{cc}
$95 \% \mathrm{Cl}(-0.003$ to -0.000$)$ & $95 \% \mathrm{Cl}(-0.013$ to -0.001$)$ \\
\hline-5 to 34 years of age & -- Total
\end{tabular}

Figure 1. Asthma mortality rates (per 100,000 population) in Brazil; 1980-2012. p.a.: per year.

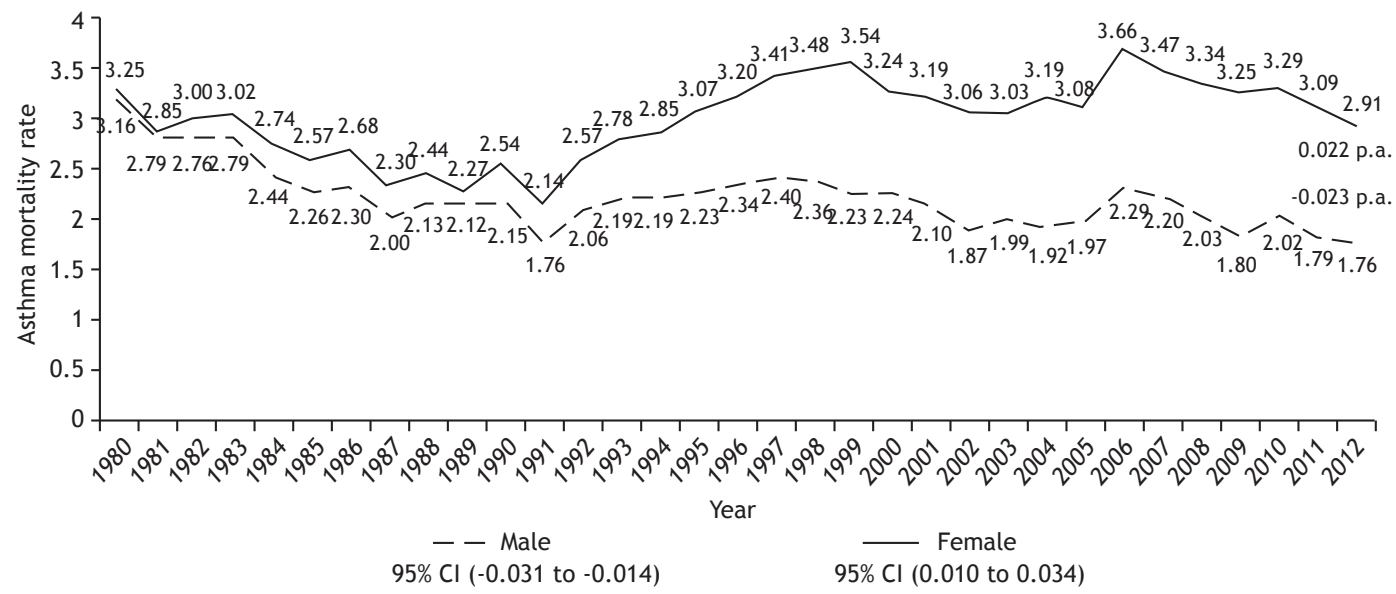

Figure 2. Asthma mortality rates (per 100,000 population) by gender in Brazil; 1980-2012. p.a.: per year. 

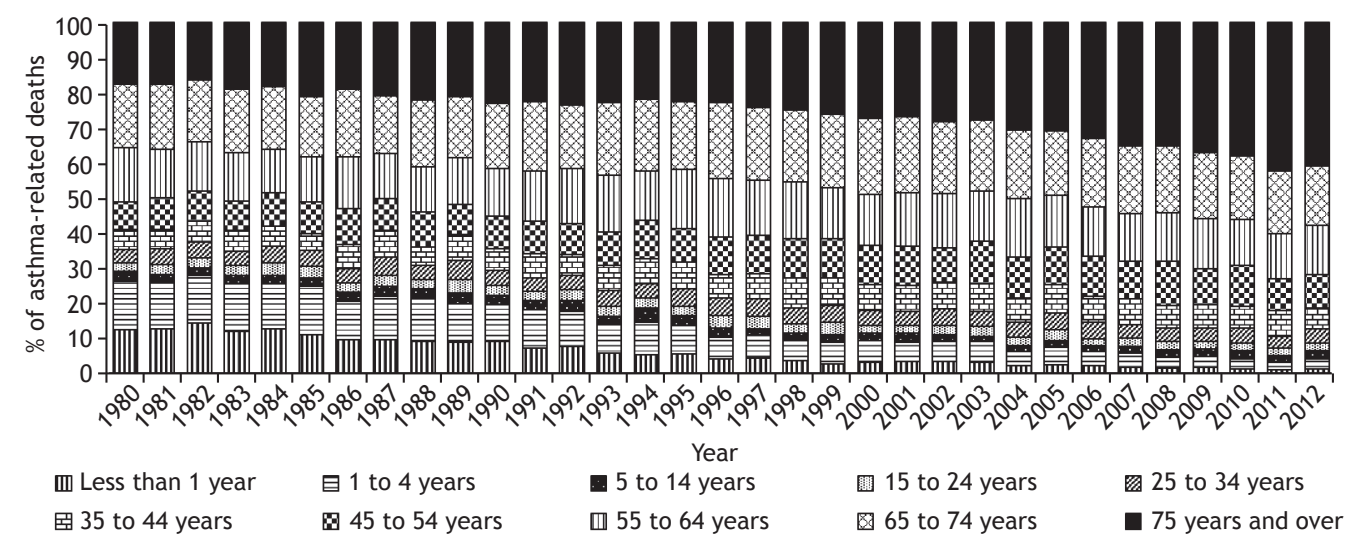

Figure 3. Proportional distribution of asthma-related deaths by age group in Brazil; 1980-2012.

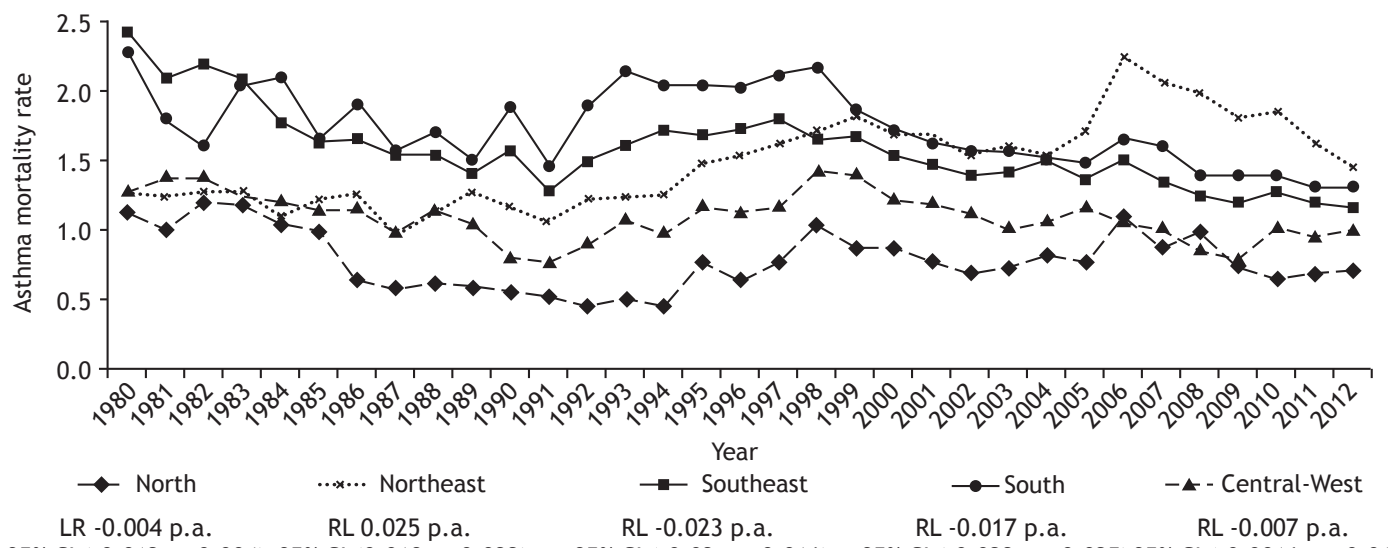
$95 \% \mathrm{Cl}(-0.012$ to 0.004$) 95 \% \mathrm{Cl}(0.018$ to 0.032$) \quad 95 \% \mathrm{Cl}(-0.03$ to -0.016$) \quad 95 \% \mathrm{Cl}(-0.023$ to -0.025$) 95 \% \mathrm{Cl}(-0.0016$ to -0.017$)$

Figure 4. Trends in asthma mortality rates by Brazilian macro-region; 1980-2012. LR: linear regression; and p.a.: per year.

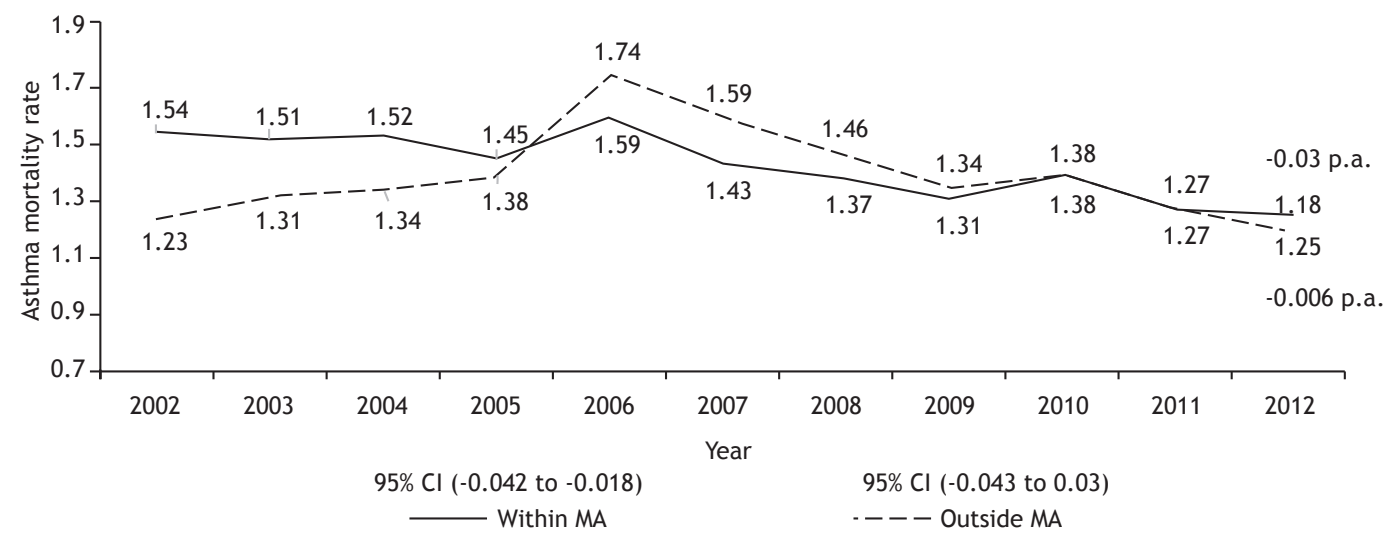

Figure 5. Temporal evolution of asthma mortality rates in municipalities within and outside metropolitan areas in Brazil; 2002-2012. p.a: per year; and MA: metropolitan areas.

because, in small municipalities outside MA, there was a downward trend in the moving averages of asthma mortality rates for this age group.

\section{DISCUSSION}

Asthma mortality rates in Brazil are high, despite the fact that they showed a downward trend during the study period, more markedly in the last 3 years.
Between 1980 and 2012, there were, on average, 2,339 asthma-related deaths per year. The decrease detected during the last decade of the study (2002-2012) was confirmed by what was observed in the population aged 5-34 years.

Analysis by macro-region showed that, on average, the South had the highest asthma mortality rates per 100,000 population (1.73), followed by the Southeast (1.58), Northeast (1.48), Central-West (1.10), and 


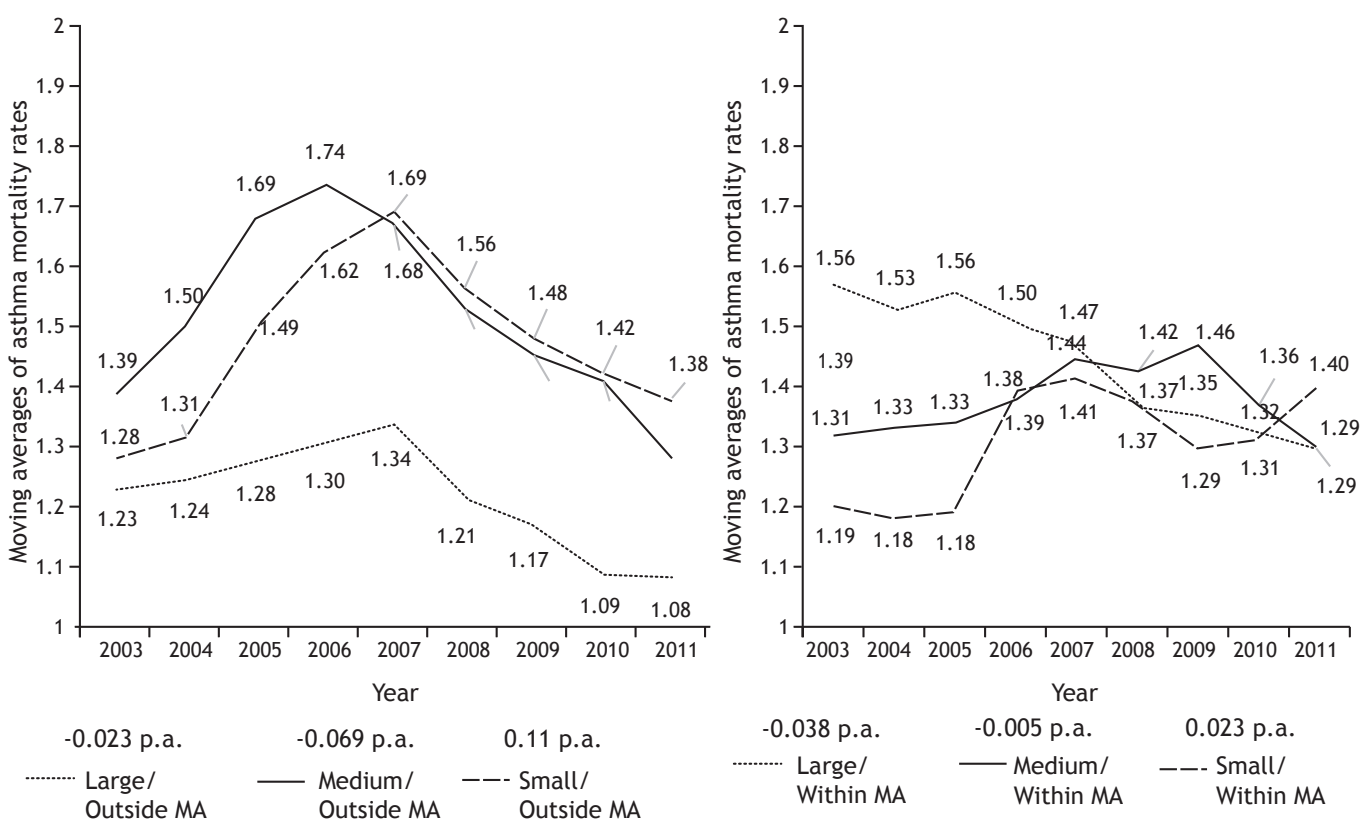

Figure 6. Moving averages of asthma mortality rates (per 100,000 population) in large, medium, and small municipalities, by whether municipalities are within or outside metropolitan areas. General population, Brazil, 2003-2011. p.a: per year; and MA: metropolitan areas.

North (0.79). Asthma mortality rates were equivalent to the national average (1.48) in the Northeast, were higher than this average in the Southeast and South, and were lower than this average in the Central-West and North. Analysis of trends in asthma mortality rates in the different macro-regions revealed a steady downward trend, except for the Northeast. Similar results were reported by Souza-Machado(15) (rates of 1.68 in 1998 and 1.32 in 2009), who also reported an increase in asthma mortality rates only in the Northeast. Regional differences in access to and quality of health care, as well as climatic, environmental, and socioeconomic differences, are possibly involved in the variety observed in asthma mortality rates among the different regions.

The difference in the asthma epidemiological situation between urban and rural environments motivated us to analyze the data collected from a municipal perspective. Consequently, we chose to use a classification that separated municipalities into urban and rural, as well as into large, medium, and small. Among the reasons for this type of data analysis is the fact that positive factors of MA, such as more developed and better equipped health care networks, are counterbalanced by negative factors, such as environmental pollution, causing an impact on mortality rates. ${ }^{(7)}$ Although classifying municipalities as being within MA introduces biases, it results in them having a population profile with greater access to services, such as public transportation, health care facilities, and schools, in comparison with municipalities outside MA. Among the possible biases of this classification is the fact that populations of small municipalities outside MA but bordering large municipalities within MA have almost the same level of access to those services as that observed for the neighboring populations.

The urban environment may be related to an increase in the prevalence of asthma. (16) This hypothesis is consistent with what was observed in a study conducted in Brazil in which the prevalence of asthma was found to be higher in adolescents who lived in urban areas than in those who lived in rural areas. ${ }^{(17)}$ However, the specialized literature reveals disagreements regarding the role of the urban environment in modulating the prevalence of asthma. ${ }^{(7)}$ A study conducted in the United States found no differences in the prevalence of asthma in MA and non-MA (classified as rural) in the state of Montana, being contrary to the argument that urbanization would increase the prevalence of asthma. ${ }^{(18)}$ At the same time, apparently, the greater availability of health care networks has a positive influence on the health of individuals in urbanized areas. ${ }^{(7)}$ A study conducted in Brazil analyzed data on the prevalence of asthma in children and adolescents in the different regions of the country (data obtained from the Brazilian National Household Survey conducted by the IBGE in the years 1998, 2003, and 2008). That study also assessed the prevalence of asthma by place of residence of individuals: urban or rural. The annual increase in the prevalence of asthma was $0.6 \%$ in the urban area and $1.8 \%$ in the rural area; therefore, the greatest increase in the prevalence of asthma occurred among rural dwellers. Although that study did not assess mortality rates, it showed the impact of asthma in rural areas in Brazil. ${ }^{(19)}$

The moving averages of asthma mortality rates showed a decrease in large municipalities within and outside MA (a large part of urban Brazil) and also a 
decrease in "rurban" Brazil; however, there was an increase in asthma mortality rates in small and medium municipalities within MA (a small part of urban Brazil). In contrast, in rural Brazil (small municipalities outside MA), there was an increase in asthma mortality. This result was confirmed by what was observed in the population aged 5-34 years, except particularly for small municipalities outside MA (rural Brazil). In those small municipalities, unlike what was observed in the general population (an increase in rates), there was a reduction in asthma mortality rates in the population aged 5-34 years. Analysis of asthma mortality data from a regional perspective indicates that asthma control measures should be given priority in part of urban Brazil (in small and medium municipalities within MA, where there is an increase in mortality) and in rural Brazil (for the general population, even if mortality rates decrease in the population aged 5-34 years).

A decline in asthma mortality rates was also observed in other countries in the same period (1980-2012), but on a larger scale. The rate of decline in Brazil $(0.67 \%)$ is lower than that reported in the United States (33\% between 1994 and 2001), (20) where the number of deaths in 2009 was $27 \%$ lower than that in 1999(21); in Brazil, the difference was $20 \%$. In Europe, asthma mortality rates decreased by $80 \%$ between 1985 and $2012^{(21)}$; in Brazil, they decreased by $16 \%$ in the same period. Between 2000 e 2011, there was a decrease of $80 \%$ in asthma-related deaths in Costa Rica(22) and a decrease of $17 \%$ in Brazil. In Cuba, asthma mortality rates per 100,000 population decreased from 4.5 in 1982 to 2.3 in 2010 (49\%), (23) a more substantial reduction than that observed in Brazil: from 1.72 to 1.38 , respectively $(20 \%)$. In Brazil, the Ministry of Health started providing free medication to patients with severe asthma in 2002,(15) and, since 2005, it has also provided free medication to patients with other forms of asthma, ${ }^{(15)}$ which is probably a relevant factor in the reduction of asthma mortality rates. $(24,25)$

Asthma mortality was lower in the younger age groups, particularly in the 5-14-year age group. Apparently, the older age groups are increasing their participation in the proportion of deaths, and the opposite is occurring among younger individuals. It would be interesting to design a study to determine whether this is due to a bias in death reporting among the elderly or whether asthma lethality has been increasing with age. Asthma mortality rates, although declining in both genders, were consistently higher among females. Higher rates in females were also found in a study conducted in the Brazilian state of Rio Grande do Sul and covering the period 1981-2003. ${ }^{(26)}$ Higher mortality rates in females have also been reported in studies conducted in other countries. ${ }^{(20,22)}$

A study by Graudenz et al.(27) presented equivalent asthma mortality rates and trends in all age groups, in addition to emphasizing a marked downward trend in rates in the last years of the study (as shown in Figure 1). A study by Campos, ${ }^{(3)}$ which reported that asthma mortality rates in the 5-34-year age group ranged from $0.18 / 100,000$ population to $0.28 / 100,000$ population between 1980 and 1998, as well as a study by Lotufo $\&$ Bensenor, ${ }^{(4)}$ which reported that asthma mortality rates in the population aged 5-34 years decreased between 1980 and 1991 but increased between 1992 and 1996, presented equivalent results. However, the study by Lotufo \& Bensenor ${ }^{(4)}$ reported a non-significant downward trend between 1997 and 2010, whereas the present study found a slight increase $(0.96 \%)$.

A study by Ponte et al., ${ }^{(28)}$ analyzing the 5-24-year age group, reported higher asthma mortality rates among individuals living in urban areas. Our study also showed an increase in asthma mortality rates in part of urban Brazil (small and medium municipalities within MA), although in large municipalities of urban Brazil (both within and outside MA) there was a decrease in the moving averages of asthma mortality rates. This result was found both for the total population and for the 5-34-year age group. The differences between the results found in the present study and those of the study by Ponte et al. ${ }^{(28)}$ are due to the fact that the latter study assessed the population aged 5-24 years and, separately, two 3-year periods (1999-2001 and 2009-2011), whereas our study analyzed 10 consecutive years (2002-2012). In addition, there were differences in the methodologies used; the present study used moving averages and simple linear regression, whereas the study by Ponte et al. ${ }^{(28)}$ used binary logistic regression.

It is of note that the Mortality Database in Brazil uses data from death certificates, which generates potential biases that may underestimate the actual mortality rates and the conclusions of the present study. ${ }^{(29)}$

In conclusion, there is dissimilarity in the behavior of asthma mortality rates from a regional perspective, with a downward trend in large municipalities (urban Brazil) and an upward trend in small and medium municipalities within MA (also urban Brazil). In rural Brazil, rates increased in the general population and decreased in the 5-34-year age group. Asthma mortality rates were consistently higher in females throughout the study period. Mortality was lowest in the 5-14-year age group, and there was a downward trend among those under 25 years of age. In contrast, rates increased in the 75 years and over age group. This last finding may be due to diagnostic biases in death reporting, but an investigation of factors involved in mortality rate dynamics was not part of the objectives of the present study. By pointing out different regional and age-related impacts, the data presented here may contribute to informing public policies aimed at asthma control.

\section{REFERENCES}


2. Lozano R, Naghavi M, Foreman K, Lim S, Shibuya K, Aboyans V, et al. Global and regional mortality from 235 causes of death for 20 age groups in 1990 and 2010: a systematic analysis for the Global Burden of Disease Study 2010. Lancet. 2012;380(9859):2095-128. https:// doi.org/10.1016/S0140-6736(12)61728-0

3. Campos HS. Mortalidade por asma no Brasil, 1980-1998. Pulmão RJ. 2003;12(4):208-16

4. Lotufo PA., Bensenor IM. Temporal trends of asthma mortality rates in Brazil from 1980 to 2010. J Asthma. 2012;49(8):779-84. https://doi. org/10.3109/02770903.2012.693237

5. Strachan D, Limb E, Pearce N, Marks G. The Burden of Asthma, In:. Global asthma report 2014, [Internet]. Auckland: Global Asthma Network; [cited 2016 Sep 24]. Available from: http://www. globalasthmareport.org/burden/mortality.php

6. Jackson R, Sears MR, Beaglehole R, Rea HH. International trends in asthma mortality: 1970 to 1985. Chest. 1988;94(5):914-8. https://doi org/10.1378/chest.94.5.914

7. Cyril S, Oldroyd JC, Renzaho A. Urbanisation, urbanicity, and health: a systematic review of the reliability and validity of urbanicity scales. BMC Public Health. 2013;13:513. https://doi.org/10.1186/1471-245813-513

8. Haahtela T, Tuomisto LE, Pietinalho A, Klaukka T, Erhola M, Kaila $M$, et al. A 10 year asthma programme in Finland: major change for the better. Thorax. 2006;61(8):663-70. https://doi.org/10.1136/ thx.2005.055699

9. Kupczyk M, Haahtela T, Cruz AA, Kuna P. Reduction of asthma burden is possible through National Asthma Plans. Allergy. 201;65(4):415-9.

10. Souza-Machado C, Souza-Machado A, Franco R, Ponte EV, Cruz AA. Impacto do PROAR (programa para o controle da asma e da rinite alérgica na Bahia) sobre a utilização de recursos de saúde, custos e morbi-mortalidade por asma em Salvador. Gaz Med Bahia [seria on the Internet]. 2008 [cited 2016 Dec 3];78(Suppl 2):[about 1 p.]. Available from: http://www.gmbahia.ufba.br/index.php/gmbahia/ article/view/750

11. Instituto Brasileiro de Geografia e Estatística (IBGE). Coordenação de Geografia. Classificação e caracterização dos espaços rurais e urbanos do Brasil : uma primeira aproximação. Rio de Janeiro: IBGE; 2017

12. Veiga JE. Cidades Imaginárias. Campinas (SP) : Autores Associados; 2002.

13. Organização Pan-Americana da Saúde (OPAS); Rede Interagencial de Informação para a Saúde. Indicadores básicos para a saúde no Brasil: conceitos e aplicações. 2nd edition. Brasília: Organização PanAmericana da Saúde; 2008

14. Wijesinghe $M$, Weatherall $M$, Perrin $K$, Crane J, Beasley $R$. International trends in asthma mortality rates in the 5- to 34-year age group: a call for closer surveillance. Chest. 2009:135(4):1045-1049. https://doi.org/10.1378/chest.08-2082

15. de Souza-Machado C, Souza-Machado A, Cruz AA. Asthma mortality inequalities in Brazil: tolerating the unbearable. ScientificWorldJournal. 2012;2012:625829. https://doi.org/10.1100/2012/625829

16. Wong GWK, Chow CM. Childhood asthma epidemiology: insights from comparative studies of rural and urban populations. Pediat Pulmonol. 2008;43(2):107-16. https://doi.org/10.1002/ppul.20755

17. Solé D, Cassol VE, Silva AR, Teche SP, Rizzato TM, Bandim LC, et al. Prevalence of symptoms of asthma, rhinitis, and atopic eczema among adolescents living in urban and rural areas in different regions of Brazil. Allergol Immunopathol (Madr). 2007;35(6):248-53. https:// doi.org/10.1157/13112991

18. Frazier J, Loveland K, Zimmerman H, Helgerson S, Harwell T. Prevalence of asthma among adults in metropolitan versus nonmetropolitan areas in Montana, 2008. Prev Chronic Dis. 2012;9:E09.

19. Wehrmeister FC, Menezes AM, Cascaes AM, Martínez-Mesa J Barros AJ. Time trend of asthma in children and adolescents in Brazil, 1998-2008. Rev Saude Publica. 2012;46(2):242-50. https://doi. org/10.1590/S0034-89102012005000008

20. Getahun D, Demissie K, Rhoads GG. Recent trends in asthma hospitalization and mortality in the United States. J Asthma. 2005;42(5):373-8. https://doi.org/10.1081/JAS-200062995

21. D'Amato G, Vitale C, Molino A, Stanziola A, Sanduzzi A, Vatrella A et al. Asthma-related deaths. Multidiscip Respir Med. 2016:11:37. https://doi.org/10.1186/s40248-016-0073-0

22. Soto-Martínez M, Avila L, Soto N, Chaves A, Celedón JC, SotoQuiros ME. Trends in hospitalizations and mortality from asthma in Costa Rica over a 12- to 15-year period. J Allergy Clin Immunol Pract. 2014;2(1):85-90. https://doi.org/10.1016/j.jaip.2013.09.010

23. Suárez-Medina R, Venero-Fernández SJ, Britton J, Fogarty AW Population-based weight loss and gain do not explain trends in asthma mortality in Cuba: A prospective study from 1964 to 2014. Respir Med. 2016;118:4-6. https://doi.org/10.1016/j.rmed.2016.07.003

24. Amaral LM, Palma PV, Leite IC. Evolution of public policies and programs for asthma control in Brazil from the perspective of consensus guidelines. J Bras Pneumol. 2012;38(4):518-25. https:// doi.org/10.1590/S1806-37132012000400015

25. Brasil. Ministério da Saúde. Departamento de Atenção Básica [homepage on the Internet]. Brasília: Ministério da Saúde; [cited 2017 Jan 2]. Portaria 2184/GM de 1 out 2013. Available from: dab.saude. gov.br/docs/legislacao/portaria2084_26_10_2005.pdf

26. Chatkin G, Chatkin JM, Fritscher CC, Cavalet-Blanco D, Bittencourt $H R$, Sears MR. Asthma mortality in southern Brazil: is there a changing trend? J Asthma. 2007:44(2):133-6. https://doi. org/10.1080/02770900601182483

27. Graudenz GS, Carneiro DP, Vieira RP. Trends in asthma mortality in the 0 - to 4-year and 5- to 34-year age groups in Brazil. J Bras Pneumol. 2017;43(1):24-31. https://doi.org/10.1590/s180637562015000000253

28. Ponte EV, Cruz AA, Athanazio R, Carvalho-Pinto R, Fernandes FLA Barreto $\mathrm{ML}$, et al. Urbanization is associated with increased asthma morbidity and mortality in Brazil. Clin Respir J. 2018;12(2):410-417. https://doi.org/10.1111/crj.12530

29. Santo AH. Asthma-related mortality, Brazil, 2000: a study using multiple causes of death [Article in Portuguese]. Cad Saude Publica. 2006;22:41-52. https://doi.org/10.1590/S0102-311X2006000100005 